\title{
Influence of socioeconomic factors on hospital readmissions for heart failure and acute myocardial infarction in patients 65 years and older: evidence from a systematic review
}

\author{
This article was published in the following Dove Press journal: \\ Clinical Interventions in Aging \\ 12 January 2015 \\ Number of times this article has been viewed
}

\section{Gianfranco Damiani' \\ Eleonora Salvatori' \\ Giulia Silvestrini' \\ Ivana Ivanova ${ }^{2}$ \\ Luka Bojovic ${ }^{3}$ \\ Lanfranco lodice' \\ Walter Ricciardi' \\ 'Department of Public Health, Università Cattolica Sacro Cuore, Rome, Italy; ${ }^{2}$ ERAWEB Project, Faculty of Medicine, Saints Cyril and Methodius University of Skopje, Skopje, Macedonia; ${ }^{3}$ ERAWEB Project, Faculty of Medicine, University of Nis, Nis, Serbia}

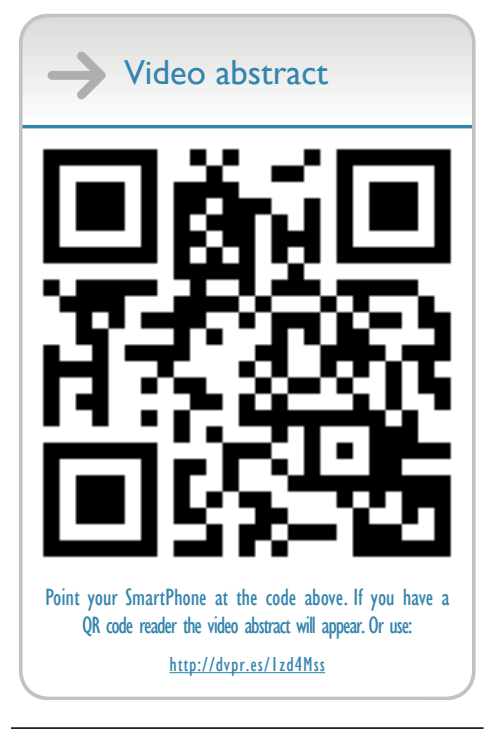

Correspondence: Gianfranco Damiani Department of Public Health, Università Cattolica Sacro Cuore, Largo F Vito,

I-00I68 Roma, Italy

Tel +39630I54396

$\mathrm{Fax}+39635001522$

Email gdamiani@rm.unicatt.it
Purpose: Cardiovascular diseases are the leading cause of death and disability worldwide. Among these diseases, heart failure (HF) and acute myocardial infarction (AMI) are the most common causes of hospitalization. Therefore, readmission for HF and AMI is receiving increasing attention. Several socioeconomic factors could affect readmissions in this target group, and thus, a systematic review was conducted to identify the effect of socioeconomic factors on the risk for readmission in people aged 65 years and older with HF or AMI.

Methods: The search was carried out by querying an electronic database and hand searching. Studies with an association between the risk for readmission and at least one socioeconomic factor in patients aged 65 years or older who are affected by HF or AMI were included. A quality assessment was conducted independently by two reviewers. The agreement was quantified by Cohen's Kappa statistic. The outcomes of studies were categorized in the short-term and the long-term, according to the follow-up period of readmission. A positive association was reported if an increase in the risk for readmission among disadvantaged patients was found. A cumulative effect of socioeconomic factors was computed by considering the association for each study and the number of available studies.

Results: A total of eleven articles were included in the review. They were mainly published in the United States. All the articles analyzed patients who were hospitalized for HF, and four of them also analyzed patients with AMI. Seven studies (63.6\%) were found for the short-term outcome, and four studies (36.4\%) were found for the long-term outcome. For the short-term outcome, race/ethnicity and marital status showed a positive cumulative effect on the risk for readmission. Regarding the educational level of a patient, no effect was found.

Conclusion: Among the socioeconomic factors, mainly race/ethnicity and marital status affect the risk for readmission in elderly people with HF or AMI. Multidisciplinary hospital-based quality initiatives, disease management, and care transition programs are a priority for health care systems to achieve better coordination.

Keywords: chronic conditions, cardiovascular disease (CVD), re-hospitalization, disparities, older patients, socioeconomic factors

\section{Introduction}

In the last decade, a demographic and epidemiological transition affected the effect of chronic diseases on the health status of the aging population. This has resulted in an increase in life expectancy ( 80 years across Organisation for Economic Co-operation and Development countries, which is a gain of more than 10 years since 1960) ${ }^{1}$ and it involves a larger proportion of the elderly population in whom chronic diseases and 
their exacerbations are becoming the major determinants of health status and the leading cause of mortality in the world, representing $60 \%$ of all deaths. ${ }^{2}$

The rise in the number of patients with a chronic disease has caused higher rates of hospitalization, ${ }^{3}$ especially for older people who reported higher rates of hospital admission and readmission compared with the general population. ${ }^{4,5}$

In the United States, among Medicare fee-for-service patients discharged from the hospital, $19.6 \%$ were rehospitalized within 30 days. ${ }^{6}$ At the end of 2011, one in five Medicare beneficiaries was readmitted to the hospital within 30 days after discharge. ${ }^{7}$

In 2005, the Medicare Payment Advisory Commission estimated that $13.3 \%$ of 30 -day hospital readmissions were potentially preventable. ${ }^{8}$ Regarding costs, the commission estimated that Medicare expenditures for potentially preventable rehospitalizations might have been as high as $\$ 12$ billion a year. ${ }^{9}$ According to Jencks et $\mathrm{al}^{6}$ readmissions cost the Medicare program $\$ 17.4$ billion annually. In Europe, available data are provided by the United Kingdom, England, and France. In 2011, the United Kingdom reported that an average of $6.5 \%$ of patients readmitted to hospitals within 30 days cost about \$2.4 billion. ${ }^{10}$ In England, between 1998-1999 and 2006-2007, the readmission rate for people aged 16-74 years rose from $7 \%$ to $9 \%$, and for people older than 75 years the rate rose from $10 \%$ to $14 \% .{ }^{11}$ The same trend was found in France. In a study conducted in nine French hospitals, among people aged 75 years and older, $14.2 \%$ of inpatients were readmitted within 30 days of discharge. ${ }^{10}$

Cardiovascular diseases are the leading causes of death and disability in the world. Among them, heart failure (HF) and acute myocardial infarction (AMI) are two of the most common causes of hospitalization (17 million deaths). ${ }^{12}$ Considering readmission after hospitalization, some studies showed that more than $50 \%$ of patients hospitalized for HF were readmitted to hospital within 6 months after discharge. ${ }^{13-15}$ According to a study conducted in 2012 in the United States, the median risk-standardized readmission rate for AMI between 2005 and 2008 was 19.9\% (95\% confidence interval [CI]: $18.8 \%-21.1 \%)$, and for HF it was $24.4 \%(95 \%$ CI: $22.3 \%-27.0 \%) .{ }^{16}$

The readmission rate was partly influenced by inadequate inpatient care and by a lack of discharge planning. ${ }^{17,18}$ There is much evidence that suggests that a patient's socioeconomic factors may contribute to poor outcomes. ${ }^{19,20}$ The role of several socioeconomic factors such as race/ethnicity, ${ }^{14,21-25}$ income, ${ }^{26,27}$ marital status, ${ }^{23,27}$ education, ${ }^{27,28}$ socioeconomic status, ${ }^{29}$ and social network, ${ }^{30}$ as predictors of or with an effect on readmissions in elderly patients with HF or AMI, were described in primary studies.

Previous systematic reviews were conducted to examine HF readmission risk models focusing on both clinical and social factors. ${ }^{20,31}$ There are no systematic reviews for which the objective was to analyze the association between socioeconomic factors and readmission rate that were specifically focused on elderly people with HF or AMI. Therefore, a systematic review was conducted to identify the effect of SE factors on the risk for readmission in people aged 65 years and older and with HF or AMI.

\section{Methods}

\section{Search strategy}

The systematic review was conducted to identify socioeconomic factors associated with readmission or rehospitalization after the suggested form of the Preferred Reporting Items for Systematic Reviews and Meta-Analyses (PRISMA). ${ }^{32}$ One electronic database (MEDLINE) was searched to identify studies published between January 1, 2000, and January 31, 2014.

To create the string of research, the elements of the PICO model ( $\mathrm{P}$, population/patient; I, intervention/indicator; $\mathrm{C}$, comparator/control; and $\mathrm{O}$, outcome) were applied. For the "P" in PICO, the focus of the research was to analyze the main outcome readmission or rehospitalization in elderly patients. Thus, the performed search included the Medical Subject Headings (MeSH) terms "aged" and "aging" and the keywords "aging," "older," "elderly," "over 65," "over 60," “over 80," and "over 85."

Because the focus of interest was a specific type of disease, the MeSH terms "HF," "heart diseases," and "stroke" and the keywords "myocardial infarct*" (truncated) and "cardiac disease" were used. For the "I," because the interest of the present review was in a range of social factors, the following keywords were used: "socioeconomic," "inequalit*," "disparit*," "ethnic*," "education*" (truncated), and "income." For the "C," the comparator was the population not exposed to a socioeconomic condition of disparity, chosen by the authors of every article. For the "O," the keywords that were used were "readmission" and "rehospitalization," and the MeSH term was "hospitalization," excluding all index admissions and planned or elective occurrences. Finally, additional studies were identified independently by the "hand search" of references from articles included in the review (snowball searching).

\section{Study selection}

The review was conducted by applying several inclusion and exclusion criteria that were defined as a priori. The review 
included studies that concerned the risk for readmission or rehospitalization, measured the association between the risk for readmission/rehospitalization and at least one socioeconomic factor (defined as ethnicity, race, education [years of school education], marital status [or living alone], and income), targeted patients aged 65 years and older, focused on patients with HF or AMI, and were published in the English language between January 1, 2000, and January 31, 2014 , because studies about the effect of socioeconomic factors on the risk for readmission in the general population have been published mainly in the last few years..$^{20,31}$ The exclusion criteria were publications without original data (reviews, editorials, or practice guidelines), experimental studies about the effect of a single intervention at readmission (eg, discharge planning programs, transitional care programs, case management programs) if they did not discuss the effect of a patient's factors on readmission or because the effect was analyzed in relation to the single intervention, and studies about psychiatric and surgical populations because the effect of socioeconomic factors on the risk for readmission or rehospitalization might require different considerations in these target populations.

\section{Review process and data collection}

To reduce bias of selection, all titles and abstracts of studies, identified by the electronic and hand search, were screened independently by two reviewers to identify potential studies for which it was appropriate to read the full text, according to the inclusion and exclusion criteria defined a priori. The same members of the research team read and selected available articles to determine the inclusion in the systematic review. Any disagreement between the reviewers regarding the relevance of a study was resolved by consensus. At the full-text level, the articles that met the inclusion criteria were reviewed in detail. For each of these articles, the reviewers extracted data about the first author, year of publication, country, title, journal, follow-up period, study design, outcome variable, number and type of population, disease, exposure variables, and main results.

\section{Data synthesis}

First, the studies were divided on the basis of the disease studied (HF and AMI). Afterward, they were categorized by the follow-up period of readmission, short-term outcome studies (30 and 90 days after discharge) and long-term outcome studies (6 months and 1 year after discharge), which formed two groups of analysis. For both groups, the association between every socioeconomic variable and the risk for readmission was reported separately for every article. Considering the condition of socioeconomic disadvantage as exposure, a positive association between the variable and the outcome was reported if there was an increase in the risk for readmission among disadvantaged patients, a negative association if there was a decrease in the risk, and no association if no effect was found.

After that, a cumulative effect of every socioeconomic factor was computed considering the association found for each study and the number of the available studies. When at least two articles with positive associations were available, a positive cumulative effect of the socioeconomic factor was considered. When at least two articles with negative associations were available, a negative cumulative effect was taken into account. When at least two articles with no association were available, no effect was taken into account.

Furthermore, inconclusive results were considered if there were at least two articles that had different results (ie, one positive and one negative [contrasting effect], one positive and one indifferent [inconclusive but promising effect], or one negative and one indifferent [inconclusive but not promising effect]).

Finally, when only one article referred to a single socioeconomic factor, results were considered insufficient.

\section{Quality assessment}

The quality of the studies included was assessed using the Strengthening the Reporting of Observational Studies in Epidemiology (STROBE) statement. The STROBE is a quality assessment checklist for observational studies and consists of 22 items. $^{33}$

For each article, the quality score was determined by selecting the items and calculating the percentage of the selected items from the total number of possible items. Studies with a quality assessment below $50 \%$ were excluded. An interrater reliability analysis using the Kappa statistic was performed to determine consistency among reviewers. ${ }^{34}$

\section{Results}

From 2,016 articles identified by the research, 1,964 studies were excluded because of their title and abstract. The remaining 52 articles were selected for full-text review, and 25 of these were excluded because the age did not meet the inclusion criteria. Another nine articles were excluded because they were about repeated hospitalizations or other types of health care use or because they analyzed the effect of an intervention on the rate of readmission. Finally, as shown in Figure 1, two articles were excluded because the 
disease did not meet the inclusion criteria, and an additional five articles were excluded because the socioeconomic factors were different from those selected for analysis. Thus, a total of eleven articles were included in the review, for a total population of $4,369,758$ individuals. The interrater reliability for the rates of the reviewers was found to be moderate (Kappa $=0.46 ; P<0.001) .{ }^{34}$

\section{Characteristics of the included studies}

Table 1 summarizes the characteristics of the included studies. They were all cohort studies, and two of them were prospective cohort studies. Among the final number of the included studies, ten were from the United States and one was from Spain. Regarding disease at admission, all the articles analyzed patients hospitalized with a principal diagnosis of
HF, and four of the articles also analyzed patients with AMI. The identification of the patients hospitalized at baseline for HF or AMI was carried out using different sources of data; most of the studies were based on International Classification of Diseases, Ninth Revision, Clinical Modification, codes at discharge (seven articles). Three studies were based on the admitting diagnosis, and only one study took data from the control group of another study. ${ }^{27}$ The main study outcome reported was "all-cause readmission," analyzed by all the articles, whereas only two of them reported the outcome "HF-specific readmission." ${ }^{24,27}$ The main follow-up period of the outcome readmission was 30 days after discharge (four articles), and the main socioeconomic factor examined in association with readmission was race/ethnicity (six articles).

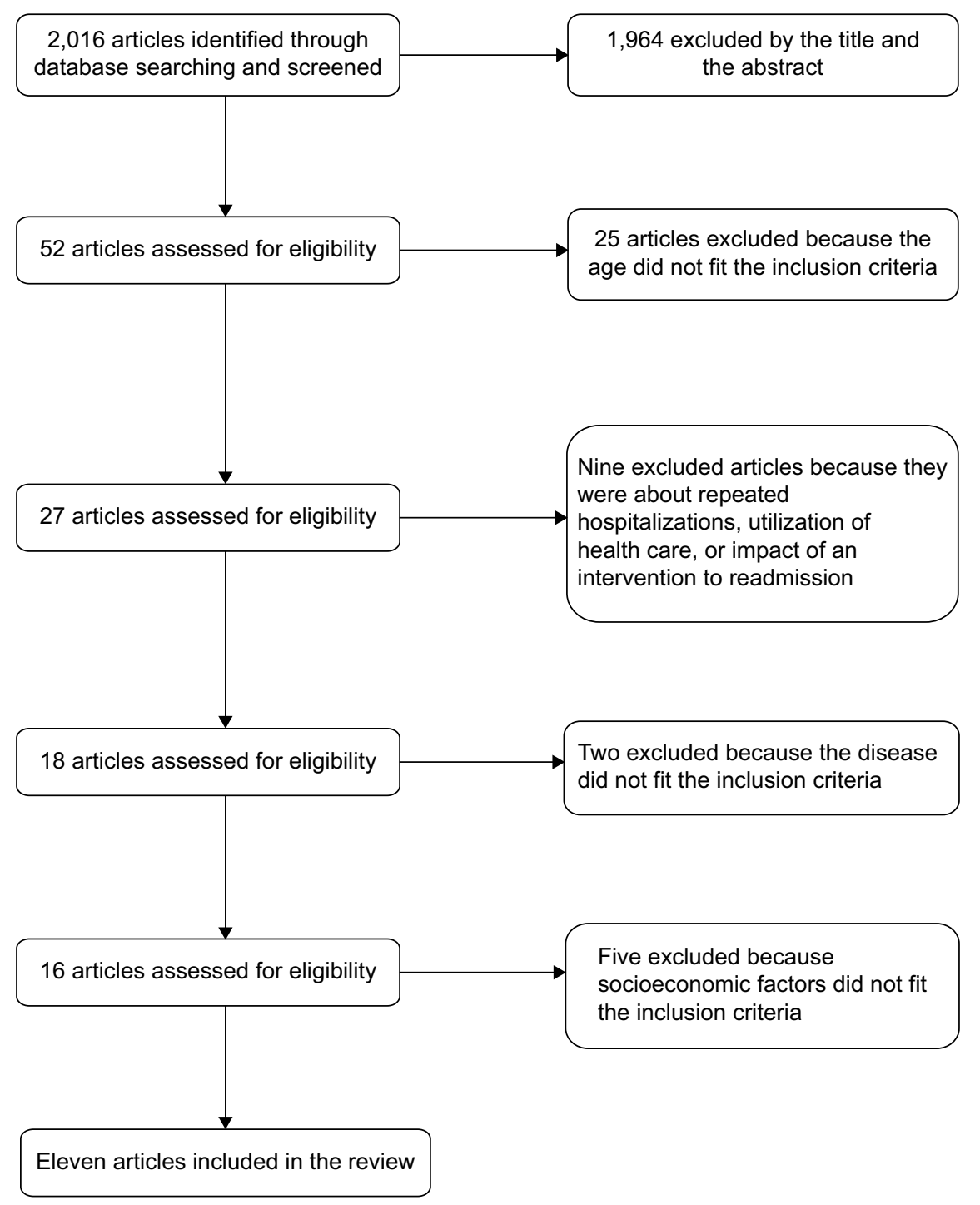

Figure I Preferred Reporting Items for Systematic Reviews and Meta-Analyses flowchart diagram of systematic reviews. 


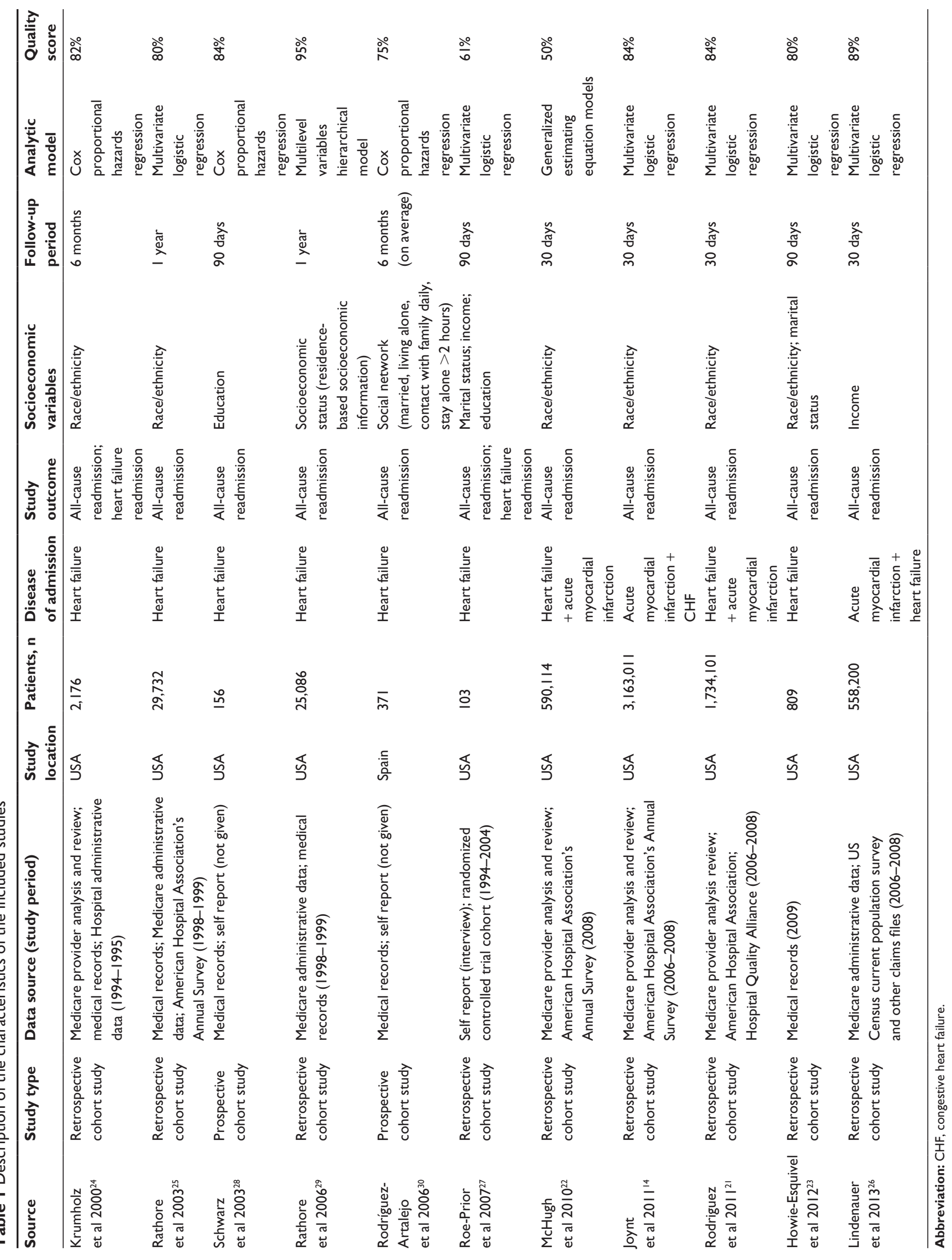




\section{Socioeconomic factors associated with readmission in populations with $\mathrm{HF}$ and $\mathrm{AMI}$}

As shown in Table 2, for the short-term outcome for both $\mathrm{HF}$ and AMI, the factor race/ethnicity was positively related to risk for readmission. For Hispanic and black people, an increase in risk for readmission was reported in comparison with white people. ${ }^{14,21-23}$ For the long-term outcome, an inconclusive but promising cumulative effect of the factor race/ethnicity was found. ${ }^{24,25}$ For the short-term outcome, the socioeconomic factor income showed an inconclusive but promising cumulative effect both for HF and AMI. ${ }^{26,27}$

For the short-term outcome, studies highlighted the positive cumulative effect of marital status as a socioeconomic factor on the risk for readmission. People without a partner or people unmarried/widowed were at increased risk for readmission. ${ }^{23,27}$ According to our findings, for the shortterm outcome, educational status was not associated with the risk for readmission in studies in which it was examined; therefore, no effect was found. ${ }^{27,28}$ Finally, for the long-term outcome, an insufficient amount of evidence was found for the composite socioeconomic factors socioeconomic status and social network. ${ }^{29,30}$

\section{Discussion}

\section{Principal findings and previous studies}

Principal findings highlighted an association between hospital readmissions and the most disadvantaged socioeconomic group in elderly patients, both for HF and AMI.

Specifically, for the short-term outcome, the socioeconomic factor race/ethnicity showed a positive cumulative effect on the risk for readmission, whereas for the long-term outcome, an inconclusive but promising cumulative effect on the risk for readmission was found. Disparities in the readmission risk for Hispanic and black people were partially a result of the quality of places in which they receive care.

Table 2 The association of socioeconomic factors and readmission

\begin{tabular}{|c|c|c|c|c|}
\hline Readmission outcome and socioeconomic factors & Studies & Association & $\begin{array}{l}\text { Cumulative } \\
\text { effect }\end{array}$ & $\begin{array}{l}\text { Quality } \\
\text { score }\end{array}$ \\
\hline \multicolumn{5}{|l|}{ Short-term outcome ( 30 days and 90 days) } \\
\hline Race/ethnicity & & & Positive & \\
\hline \multirow[t]{2}{*}{ Hispanic vs white } & Rodriguez et al $2011 ;{ }^{21}$ & + & & $84 \%$ \\
\hline & McHugh et al $2010^{22}$ & + & & $50 \%$ \\
\hline \multirow[t]{2}{*}{ Black vs white } & Joynt et al, 20I I; $;^{14}$ & + & & $84 \%$ \\
\hline & McHugh et al $2010^{22}$ & + & & $50 \%$ \\
\hline Not white (black, Hispanic, Asian) vs white & Howie-Esquivel et al $2012^{23}$ & $=$ & & $80 \%$ \\
\hline Income & & & $\begin{array}{l}\text { Inconclusive } \\
\text { but promising }\end{array}$ & \\
\hline Low quarters of income versus high quarters of income & Lindenauer et al $2013^{26}$ & + & & $89 \%$ \\
\hline Low versus high income & Roe-Prior et al $2007^{27}$ & $=$ & & $61 \%$ \\
\hline Marital status & & & Positive & \\
\hline Not partnered versus partnered & Howie-Esquivel et al $2012^{23}$ & + & & $80 \%$ \\
\hline Unmarried/widowed versus married & Roe-Prior et al $2007^{27}$ & + & & $61 \%$ \\
\hline Education & & & No effect & \\
\hline Less than high school versus post-high school & Roe-Prior et al $2007^{27}$ & $=$ & & $61 \%$ \\
\hline $\begin{array}{l}\text { Less than high school graduate versus post-high school } \\
\text { graduate }\end{array}$ & Schwarz et al $2003^{28}$ & $=$ & & $84 \%$ \\
\hline \multicolumn{5}{|l|}{ Long-term outcome (6 months and I year) } \\
\hline Race/ethnicity & & & $\begin{array}{l}\text { Inconclusive } \\
\text { but promising }\end{array}$ & \\
\hline Other versus white & Krumholz et al $2000^{24}$ & $=$ & & $82 \%$ \\
\hline Black versus white & Rathore et al $2003^{25}$ & + & & $80 \%$ \\
\hline Socioeconomic status & & & $\begin{array}{l}\text { Insufficient } \\
\text { evidence }\end{array}$ & \\
\hline Lower versus higher class of socioeconomic status & Rathore et al $2006^{29}$ & + & & $95 \%$ \\
\hline Social network & & & $\begin{array}{l}\text { Insufficient } \\
\text { evidence }\end{array}$ & \\
\hline Moderate/low versus high social network & Rodríguez-Artalejo et al $2006^{30}$ & + & & $75 \%$ \\
\hline
\end{tabular}

Notes: + stands for a positive association and = stands for no association. 
For these minority communities, there was a lack of continuity and coordination of care, which resulted in limited access to primary care, and in particular, access to postdischarge care, poorer outpatient follow-up, and limited use of preventive services. Furthermore, they were frequently inarticulate in English as a second language. In the end, the variable of race itself could affect cardiovascular disease process, but this factor alone could not explain the excess readmission risk. ${ }^{14,35-38}$

For the short-term outcome, the factor of marital status showed a positive cumulative effect on the risk for readmission. In the literature, it was shown that married or partnered people were more likely to have a primary care provider and to use preventive health services, and therefore, they could manage their $\mathrm{HF}$ and coexisting conditions better, reducing the risk for readmission. ${ }^{27}$

Furthermore, for the short-term outcome, inconclusive but promising evidence was found for the association between the socioeconomic factor of income and readmission.

These findings are consistent with considerations made previously by other reviews on the general population affected by HF, but not stratified by age. Previous systematic reviews found that the socioeconomic factors of race/ ethnicity and living situation had a positive association with readmission in the general population with $\mathrm{HF}^{20,31}$ and with Medicare patients in general, ${ }^{39}$ which is in line with our findings. The factor income showed inconclusive, but promising, evidence about the association with readmission, similar to the findings in the other reviews..$^{20,31}$

Regarding educational level, for the short-term outcome, no effect of this factor on the risk for readmission was found, so it seems that no association is present, and the same consideration was made in other reviews. ${ }^{20,31}$

Finally, variables about the type of treatment received by the patients might be important to partially explain the risk for readmission, especially for AMI. ${ }^{40}$ However, only one of the four studies included in the review ${ }^{26}$ that focused on patients with AMI considered these variables, within the model of analysis, to adjust the results. Therefore, it was not possible to determine whether the treatments received by the patients could affect the association found between the socioeconomic factors and the risk for readmission.

\section{Limitations and strengths}

First of all, this systematic review analyzed only one electronic database (Medline), and it is possible that some studies were not included. To reduce this risk, the snowball searching technique was also used to conduct a hand search.
Second, as socioeconomic factors are defined in different ways and there is not a MeSH term for this category, some articles may have been lost. To minimize this risk, extensive research was conducted about the main socioeconomic factors that were analyzed in the scientific literature. Taking that approach made it possible to determine a disparity in the general use of health care services. Afterward, the selected socioeconomic factors were included in the string of research. Furthermore, given the variability of included studies, mainly resulting from the different periods of follow-up considered, it was not possible to synthesize the results for each outcome investigated, and summary statistics could not be used. Nevertheless, using tables, the results have been organized in an analytical and rigorous way to facilitate an interpretation.

Finally, as the present systematic review was restricted to an elderly population with specific diseases (HF and AMI), and almost all of the studies were conducted in the United States, where the health system is different from in other countries, the generalizability to the entire population or to the population of other countries should be done with caution.

Nonetheless, this systematic review synthesizes evidence about relationships between socioeconomic factors and readmission, focusing on elderly people with HF or AMI.

\section{Policy implication to avoid rehospitalization}

These results underline the need for improvement in the coordination and continuity of care from inpatient to outpatient settings, as well as the need to reduce adverse events such as readmission, especially for people with complex care needs who are at higher risk. In fact, avoiding rehospitalization has been recognized by policymakers as a goal that both improves quality and reduces health care costs. ${ }^{41}$

Much evidence from scientific literature has proven the effectiveness and success of strategies that included multidisciplinary hospital-based quality initiatives, disease management programs, and care transition interventions in the reduction of the risk for readmission in patients with HF. ${ }^{42,43}$ Furthermore, specific strategies focused on patients with $\mathrm{HF}$ and on a follow-up period of 30 days are associated with a reduction in the readmission rate. ${ }^{36,44}$

Considering the effect of socioeconomic factors on readmission found in this review, it might be important to introduce, in the context of health care policies and practice, appropriate indicators aimed at measuring and understanding the role of socioeconomic disparities on the risk for readmission in different groups of people. On the basis of 
these indicators, it would be possible to define strategies and interventions to support the period after discharge and avoid rehospitalization, particularly for elderly people with HF or AMI in a specific socioeconomic condition of disadvantage.

\section{Further developments}

Future studies with a focus on elderly people with HF or AMI are needed to take into account a patient's socioeconomic factors associated with readmission. On the one hand, a clarification of the relationships among income, education, socioeconomic status, and social network with readmission must be presented because there were not enough studies that addressed those issues in the literature that was examined. On the other hand, there is a requirement to understand whether other socioeconomic factors studied in the general population can also affect the risk for readmission in the specific population of elderly patients with HF or AMI. Furthermore, it is essential to introduce specific indicators to measure the role of socioeconomic disparities. On the basis of these disparities, future studies are needed to define strategies and interventions, such as multidisciplinary hospital-based quality initiatives, disease management programs, or care transition interventions targeted for elderly people with HF or AMI in a specific socioeconomic condition of disadvantage and to evaluate their effectiveness in the reduction of readmission risk and in the decrease of socioeconomic disparities.

\section{Conclusion}

Among the investigated socioeconomic factors, race/ ethnicity and marital status are the main factors that affect the risk for readmission in elderly people with HF or AMI. Future research is needed to clarify the association between readmission and socioeconomic factors that have not been studied. Furthermore, the introduction of indicators to measure the role of socioeconomic factors on the risk for readmission, and after that, the definition of multidisciplinary hospitalbased quality initiatives, disease management programs, care transition interventions, and other strategies and interventions focused on all elderly people with HF and AMI, are a priority for health care systems to achieve better coordination and continuity of care that will prevent rehospitalization.

\section{Acknowledgment}

The authors thank Joan C Stevenson for the revision of the manuscript. This article is based on a research program titled "Quality and equity of local health care delivered to people affected by chronic diseases: organizational and impact analysis of proactive models implemented at the regional level", and funded by a public grant provided by the Italian National Agency for Regional Health Services.

\section{Author contributions}

All authors made substantial contributions to conception and design, acquisition of data, or analysis and interpretation of data. All authors took part in either drafting or revising the article critically for important intellectual content. All authors approved the final version to be published.

\section{Disclosure}

The authors report no conflicts of interest in this work.

\section{References}

1. Organisation for Economic Co-operation and Development. OECD Better Life Index. Paris, France: Organisation for Economic Co-operation and Development. Available from: http://www. oecdbetterlifeindex.org/topics/health/. Accessed July 14, 2014.

2. World Health Organization. Chronic Diseases and Health Promotion. Geneva, Switzerland: World Health Organization. Available from: http://www.who.int/chp/en/. Accessed July 14, 2014.

3. AARP Public Policy Institute. Chronic Care: A Call to Action for Health Reform, 2009. Washington, DC: AARP. Available from: http:// assets.aarp.org/rgcenter/health/beyond_50_hcr.pdf. Accessed July 14, 2014.

4. Courtney M, Edwards H, Chang A, Parker A, Finlayson K, Hamilton K. Fewer emergency readmissions and better quality of life for older adults at risk of hospital readmission: a randomized controlled trial to determine the effectiveness of a 24-week exercise and telephone follow-up program. J Am Geriatr Soc. 2009;57(3):395-402.

5. Rich MW, Beckham V, Wittenberg C, Leven CL, Freedland KE, Carney RM. A multidisciplinary intervention to prevent the readmission of elderly patients with congestive heart failure. $N$ Engl J Med. 1995;333(18):1190-1195.

6. Jencks SF, Williams MV, Coleman EA. Rehospitalizations among patients in the Medicare fee-for-service program. $N$ Engl $J$ Med. 2009;360(14):1418-1428.

7. Lonowski S. Improving Care Transitions: A Strategy For Reducing Readmissions. Available from: http://civhc.org/getmedia/475510fcff67-4655-a915-c9539117eb2f/Care-Transitions-Policy-BriefFINAL_9.2012.pdf.aspx. Accessed July 14, 2014.

8. Axon RN, Williams MV. Hospital readmission as an accountability measure. JAMA. 2011;305(5):504-505.

9. Medicare Payment Advisory Commission. Report to the Congress: Reforming the Delivery System. Washington, DC: Medicare Payment Advisory Commission; 2008. Available from: http://www.medpac. gov/documents/reports/Jun08_EntireReport.pdf?sfvrsn=0. Accessed July 14, 2014.

10. The Burrill Report. Hospital Readmissions in Europe. Available from: http://www.burrillreport.com/content/Hospital-ReadmissionsEurope_HiRes.pdf. Accessed July 14, 2014.

11. Nolte E, Roland M, Guthrie S, Brereton L. Preventing Emergency Readmissions to Hospital: A Scoping Review. Santa Monica, CA: Rand Corporation; 2012. Available from: http://www.rand.org/pubs/ technical_reports/TR1198.html. Accessed July 14, 2014.

12. World Health Organization. Global Health Observatory (GHO). Deaths from CVD and diabetes. Geneva, Switzerland: World Health Oranization. Available from: http://www.who.int/gho/ncd/mortality_morbidity/ cvd/en/. Accessed July 14, 2014. 
13. Krumholz HM, Merrill AR, Schone EM, et al. Patterns of hospital performance in acute myocardial infarction and heart failure 30-day mortality and readmission. Circ Cardiovasc Qual Outcomes. 2009;2(5):407-413.

14. Joynt KE, Orav EJ, Jha AK. Thirty-day readmission rates for Medicare beneficiaries by race and site of care. JAMA. 2011;305(7):675-681.

15. Chun S, Tu JV, Wijeysundera HC, et al. Lifetime analysis of hospitalizations and survival of patients newly admitted with heart failure. Circ Heart Fail. 2012;5(4):414-421.

16. Roger VL, Go AS, Lloyd-Jones DM, et al; American Heart Association Statistics Committee and Stroke Statistics Subcommittee. Executive summary: heart disease and stroke statistics - 2012 update: a report from the American Heart Association. Circulation. 2012;125(1):188-197.

17. Coleman EA. Falling through the cracks: challenges and opportunities for improving transitional care for persons with continuous complex care needs. J Am Geriatr Soc. 2003;51(4):549-555.

18. Naylor M, Keating SA. Transitional care. Am J Nurs. 2008;108(9) (suppl):58-63.

19. Kansagara D, Englander H, Salanitro A, et al. Risk prediction models for hospital readmission: a systematic review. JAMA. 2011;306(15):1688-1698.

20. Calvillo-King L, Arnold D, Eubank KJ, et al. Impact of social factors on risk of readmission or mortality in pneumonia and heart failure: systematic review. J Gen Intern Med. 2013;28(2):269-282.

21. Rodriguez F, Joynt KE, López L, Saldaña F, Jha AK. Readmission rates for Hispanic Medicare beneficiaries with heart failure and acute myocardial infarction. Am Heart J. 2011;162(2):254-261.e3.

22. McHugh MD, Carthon JMB, Kang XL. Medicare readmissions policies and racial and ethnic health disparities: a cautionary tale. Policy Polit Nurs Pract. 2010;11(4):309-316.

23. Howie-Esquivel J, Spicer JG. Association of partner status and disposition with rehospitalization in heart failure patients. Am J Crit Care 2012;21(3):e65-e73.

24. Krumholz HM, Chen YT, Wang Y, Vaccarino V, Radford MJ, Horwitz RI. Predictors of readmission among elderly survivors of admission with heart failure. Am Heart J. 2000;139(1 Pt 1):72-77.

25. Rathore SS, Foody JM, Wang Y, et al. Race, quality of care, and outcomes of elderly patients hospitalized with heart failure. JAMA 2003;289(19):2517-2524.

26. Lindenauer PK, Lagu T, Rothberg MB, et al. Income inequality and 30 day outcomes after acute myocardial infarction, heart failure, and pneumonia: retrospective cohort study. BMJ. 2013;346(feb14 3):f521.

27. Roe-Prior P. Sociodemographic variables predicting poor post-discharge outcomes for hospitalized elders with heart failure. Medsurg Nurs. 2007; 16(5):317-321

28. Schwarz KA, Elman CS. Identification of factors predictive of hospital readmissions for patients with heart failure. Heart Lung. 2003;32(2):88-99.

29. Rathore SS, Masoudi FA, Wang Y, et al. Socioeconomic status, treatment, and outcomes among elderly patients hospitalized with heart failure: findings from the National Heart Failure Project. Am Heart J. 2006;152(2):371-378
30. Rodríguez-Artalejo F, Guallar-Castillón P, Herrera MC, et al. Social network as a predictor of hospital readmission and mortality among older patients with heart failure. J Card Fail. 2006;12(8):621-627.

31. Ross JS, Mulvey GK, Stauffer B, et al. Statistical models and patient predictors of readmission for heart failure: a systematic review. Arch Intern Med. 2008;168(13):1371-1386.

32. Moher D, Liberati A, Tetzlaff J, Altman DG; PRISMA Group. Preferred reporting items for systematic reviews and meta-analyses: the PRISMA statement. Ann Intern Med. 2009;151(4):264-269, W64.

33. von Elm E, Altman DG, Egger M, Pocock SJ, Gøtzsche PC, Vandenbroucke JP; STROBE Initiative. The Strengthening the Reporting of Observational Studies in Epidemiology (STROBE) statement: guidelines for reporting observational studies. Lancet. 2007;370(9596):1453-1457.

34. Landis JR, Koch GG. The measurement of observer agreement for categorical data. Biometrics. 1977;33(1):159-174.

35. Reschovsky JD, O’Malley AS. Do primary care physicians treating minority patients report problems delivering high-quality care? Health Aff (Millwood). 2008;27(3):w222-w231.

36. Hernandez AF, Greiner MA, Fonarow GC, et al. Relationship between early physician follow-up and 30-day readmission among Medicare beneficiaries hospitalized for heart failure. JAMA. 2010;303(17):1716-1722.

37. Gaskin DJ, Spencer CS, Richard P, Anderson GF, Powe NR, Laveist TA. Do hospitals provide lower-quality care to minorities than to whites? Health Aff (Millwood). 2008;27(2):518-527.

38. Hasnain-Wynia R, Baker DW, Nerenz D, et al. Disparities in health care are driven by where minority patients seek care: examination of the hospital quality alliance measures. Arch Intern Med. 2007;167(12):1233-1239.

39. Arbaje AI, Wolff JL, Yu Q, Powe NR, Anderson GF, Boult C. Postdischarge environmental and socioeconomic factors and the likelihood of early hospital readmission among community-dwelling Medicare beneficiaries. Gerontologist. 2008;48(4):495-504.

40. Yale New Haven Health Services Corporation/Center for Outcomes Research and Evaluation. 2013 Measures Updates and Specifications: Acute Myocardial Infarction, Heart Failure, and Pneumonia 30-Day Risk-Standardized Mortality Measure (Version 7.0). New Haven, CT: Yale New Haven Health Services Corporation/Center for Outcomes Research and Evaluation; 2013. Available from: http://sepas.srhs. com/wp-content/uploads/2014/01/Mort-AMI-HF-PN_MeasUpdtRept_ v7.pdf. Accessed September 1, 2014.

41. Hansen LO, Young RS, Hinami K, Leung A, Williams MV. Interventions to reduce 30-day rehospitalization: a systematic review. Ann Intern Med. 2011;155(8):520-528.

42. Fleming LM, Kociol RD. Interventions for heart failure readmissions: successes and failures. Curr Heart Fail Rep. 2014;11(2):178-187.

43. Naylor MD, Aiken LH, Kurtzman ET, Olds DM, Hirschman KB. The care span: The importance of transitional care in achieving health reform. Health Aff (Millwood). 2011;30(4):746-754.

44. Bradley EH, Curry L, Horwitz LI, et al. Hospital strategies associated with 30-day readmission rates for patients with heart failure. Circ Cardiovasc Qual Outcomes. 2013;6(4):444-450.
Clinical Interventions in Aging

\section{Publish your work in this journal}

Clinical Interventions in Aging is an international, peer-reviewed journal focusing on evidence-based reports on the value or lack thereof of treatments intended to prevent or delay the onset of maladaptive correlates of aging in human beings. This journal is indexed on PubMed Central, MedLine,
CAS, Scopus and the Elsevier Bibliographic databases. The manuscript management system is completely online and includes a very quick and fair peer-review system, which is all easy to use. Visit http://www.dovepress. com/testimonials.php to read real quotes from published authors. 